\title{
Optimal long-term antithrombotic management of atrial fibrillation: life cycle management
}

\author{
R. Pisters ${ }^{1}$ A. Elvan ${ }^{2}$ H. J. G. M. Crijns ${ }^{3}$ M. E. W. Hemels ${ }^{1,4}$ \\ Published online: 2 May 2018 \\ (c) The Author(s) 2018
}

\begin{abstract}
Optimal antithrombotic management of atrial fibrillation equals balancing between prevention of arterial thromboembolism, predominantly ischaemic stroke, and haemorrhagic complications. Over time different antithrombotic agents and strategies have been developed. At present, non-vitamin K antagonist oral anticoagulants (NOACs) are the first-line therapy for stroke prevention in patients with non-valvular atrial fibrillation (i.e. without a mechanical valve prosthesis or rheumatic heart disease). Considering the impact of the suboptimal adoption of recommended oral anticoagulant therapy, as experienced with the previous first-line vitamin $\mathrm{K}$ antagonists, this review focuses on adequate use of NOACs. As such, we address the most important and clinically challenging issues in the antithrombotic life cycle management for long-term stroke prevention in atrial fibrillation.
\end{abstract}

Keywords Atrial fibrillation $\cdot$ Anticoagulation $\cdot$ Stroke risk $\cdot$ Bleeding risk $\cdot$ NOAC $\cdot$ VKA

\section{Introduction}

Ischaemic stroke is probably the most infamous complication of non-valvular atrial fibrillation (AF). Untreated, the average annual stroke risk is $5 \%$ and exceeds $7 \%$ if clinically undetected strokes and transient ischaemic attacks (TIAs) are taken into account [1]. These observations triggered an ongoing search for the optimal antithrombotic strategy: a practical approach for maximum stroke and bleeding risk reduction. Anno 2018, this strategy consists of 1) AF documentation, 2) long-term stroke risk assessment using the $\mathrm{CHA}_{2} \mathrm{DS}_{2}$-VASc score (congestive heart failure, hypertension, age $\geq 75$ years [doubled], diabetes mellitus, prior stroke [doubled], vascular disease, age 65-74 years and female sex), 3) modifiable stroke and bleeding risk factor identification and 4) appropriate initiation of a non-

M. E. W. Hemels

mhemels@rijnstate.nl

1 Department of Cardiology, Rijnstate Arnhem, Arnhem, The Netherlands

2 Department of Cardiology, Isala Hospital Zwolle, Zwolle, The Netherlands

3 Department of Cardiology, Maastricht University Medical Centre, Maastricht, The Netherlands

4 Department of Cardiology, Radboud University Medical Centre Nijmegen, Nijmegen, The Netherlands vitamin $\mathrm{K}$ antagonist oral anticoagulant (NOAC), unless contra-indicated [2].

The above-mentioned integrated AF treatment approach appears simple and straightforward and appropriate use results in a very substantial stroke and mortality reduction. However, inappropriate use or deprivation of patients from an effective strategy may lead to suboptimal clinical outcome. The latter is one specific lesson learned from the vitamin K antagonist (VKA) era [3]. This review focuses on adequate use of NOACs to prevent history from repeating itself. As such, we address the most important and clinically challenging issues in antithrombotic life cycle management for long-term stroke prevention in AF (Fig. 1).

\section{Initiation of long-term antithrombotic management}

\section{AF documentation and indication for oral anticoagulation (OAC)}

Given the significant antithrombotic therapeutic consequences and their potential sequelae, it all starts with unequivocal electrocardiographic documentation of $\mathrm{AF}$. Next, identifying clinical AF duration and type, adequate treatment of symptoms, underlying cardiovascular and pulmonary disease and/or other triggers. However, it is worth noting that the indication for OAC is independent of the 


\section{KEY MESSAGE}

The ideal follow-up strategy for patients using NOACs should include monitoring to avoid under- and overdosing. This includes assessment of renal function, body weight, and modifiable bleeding risk factors. Other important aspects are education, of both patient and physician, and interdisciplinary communication.

type of AF. A clinically challenging scenario is the patient with secondary AF: a paroxysmal episode only documented during a temporary, reversible disease state (e.g. thyrotoxicosis, post-operative inflammation, and infections such as pneumonia). These patients have both a higher risk of 'future' AF and worse long-term cardiovascular outcomes [4]. However, optimal long-term antithrombotic management of secondary AF remains unclear in the absence of randomised controlled trials (RCTs). Despite the association of OAC use with reduced long-term mortality in postoperative AF patients [4], appropriate risk assessment, timing and patient preference need to be taken into account. Currently, the same accounts for atrial sensing of asymptomatic high atrial rate episodes by implantable devices. There is supporting evidence that the majority of these patients with 'subclinical AF' also have an increased stroke risk $[5,6]$, it is still unclear whether and when they benefit from OAC, also considering the bleeding risk. OAC has to be considered in patients with two additional $\mathrm{CHA}_{2} \mathrm{DS}_{2}$ VASc risk factors (i.e. $\geq 2$ in males, $\geq 3$ in females) and an $\mathrm{AF}$ burden $>24 \mathrm{~h}$ (if there are no contraindications) [7]. Lower duration may merit OAC if multiple risk factors are present.

\section{Short-term stroke risk}

Somewhat artificially we can differentiate a short- and longterm stroke risk. The former has a different, more 'mechanical' pathophysiology. Functional left atrial (appendage) standstill during AF is followed by resolution of atrial stunning upon sinus rhythm restoration [8]. This mechanism is thought to be responsible for the post-cardioversion strokes, nearly all occurring within 10 days after cardioversion [9]. This relates to the known proportional relationship between the duration of the AF episode and the time until normal atrial contraction returns $[8,10]$. Similarly, there is a risk of peri-ablation left atrial appendage thrombus. The optimal management of this short-term stroke risk is a separate entity and depends on the planned procedure, i.e. cardioversion or ablation.

\section{Long-term stroke risk assessment}

The vascular nature of AF is underlined by the high prevalence of cardiovascular co-morbidities, which represent the intrinsic long-term stroke risk. The most important independent stroke risk factors are incorporated into the $\mathrm{CHA}_{2} \mathrm{DS}_{2} \mathrm{VASc}$ score and its use is recommended for stroke risk assessment in AF patients [2]. Considering the increasing aging of our society it is important to emphasise that age is an extremely strong, continuous, risk factor for stroke [11] and aging potentiates other risk factors such as heart failure. Therefore, the $\mathrm{CHA}_{2} \mathrm{DS}_{2} \mathrm{VASc}$ score should be reassessed over time [12]. Untreated, one out of every four octogenarians with AF suffers a stroke during their remaining lifetime [1]. Still, across various health care settings studies demonstrated age, frailty and dementia to be some of the strongest independent predictors of withholding anticoagulation in the eldest elderly [13-15]. However, in these patients the key question is not whether, but how we should organise optimal anticoagulation.

\section{Major bleeding risk assessment}

The downside of any antithrombotic drug is an increase of patients' intrinsic risk of bleeding. It therefore makes sense to identify bleeding risk factors. Practical bleeding risk scores, such as HASBLED [16], assist in particular with identifying modifiable risk factors. Thereby minimising the risk of major bleeding during OAC treatment. However, we should keep in mind that the available risk scores fail to capture important frailty aspects in the eldest elderly with AF [17] and, similarly in elderly with venous thromboembolism [13]. Here, previous reports demonstrated that age itself proved to be a strong determinant of risk. Especially the eldest elderly (85+) appear to have a substantial increased risk of major bleeding [18, 19]. This enhanced bleeding risk also applies for patients with a poor quality of anticoagulation (i.e. time in therapeutic range [TTR] $<65 \%$, patients spent a median $14 \%, 71 \%$, and $15 \%$ of time below, within, and above the intended therapeutic range, respectively) [20]. 
Fig. 1 Oral anticoagulation life-cycle management in atrial fibrillation

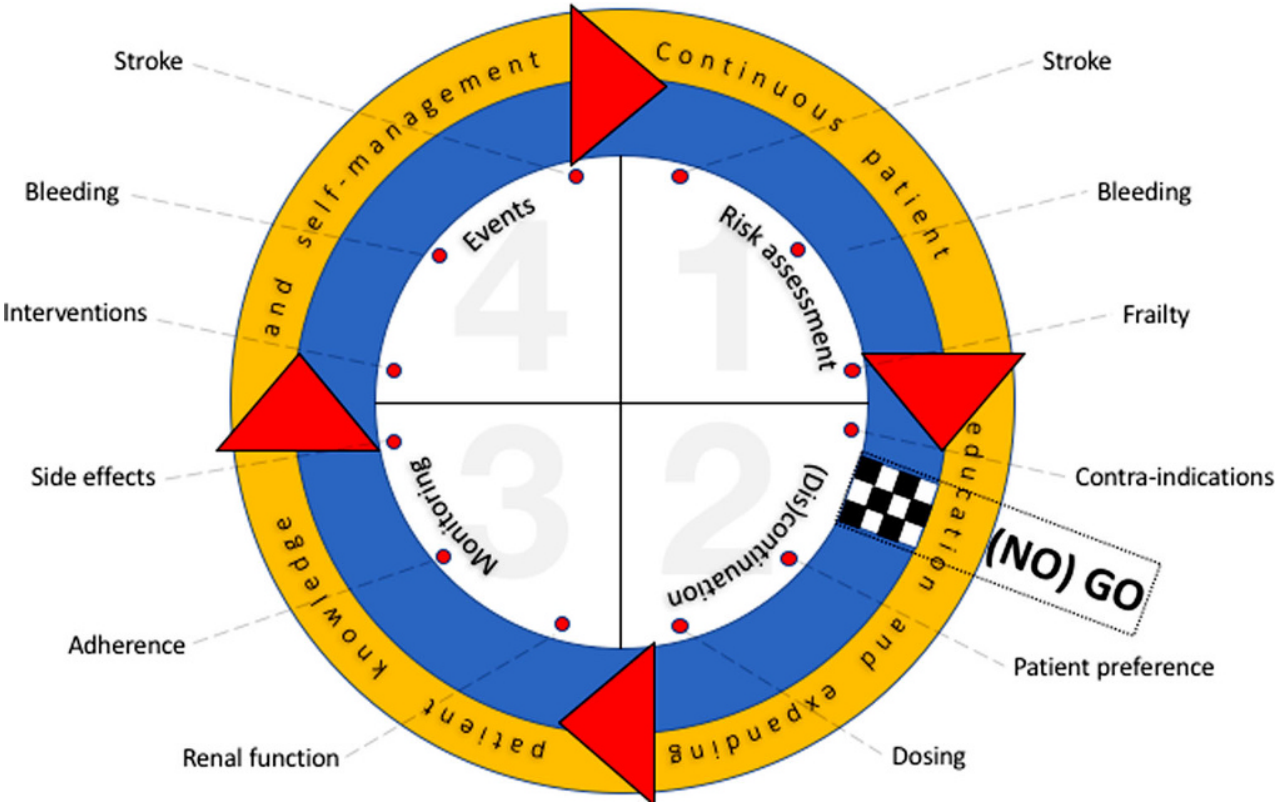

Table 1 Preconditions for effective shared decision making

\begin{tabular}{lll}
\hline Motivation & Communication & Infrastructure \\
\hline Willingness & $\begin{array}{l}\text { Stroke risk and } \\
\text { impact }\end{array}$ & ICT support \\
Social support & $\begin{array}{l}\text { Bleeding risk and } \\
\text { impact }\end{array}$ & Substitution of care \\
Cognitive capability & On a patient level & Time \\
\hline
\end{tabular}

\section{Choosing anticoagulation: shared decision making}

According to the current European Society of Cardiology/ European Heart Rhythm Association (ESC/EHRA) guidelines men and women with a $\mathrm{CHA}_{2} \mathrm{DS}_{2}$ VASc score of 2 and 3 , respectively, clearly benefit from OAC. In case of a $\mathrm{CHA}_{2} \mathrm{DS}_{2} \mathrm{VASc}$ score of 1 in men and 2 in women, OAC is likely to provide net clinical benefit and individual characteristics and patients' preferences should be considered [2]. However, a primary care study among 260 AF patients aged 70-85 years that used decision analysis regarding antithrombotic treatment preference showed that approximately half of the patients with a preference for OAC did not receive it [21]. On the other hand, $47 \%$ of patients were not being prescribed warfarin although the results of their decision analysis suggested they wanted to be. A researcher-administered questionnaire study using a fictional $\mathrm{AF}$ patient and pictograms to display the 10-year risk of stroke showed that $100 \%$ of the elderly chose OAC over no treatment. However, when the necessity of many tablets with multiple blood tests, alcohol restrictions and an increasing risk of intracranial haemorrhage was introduced, the choice for anticoagulation dropped. A daily tablet cor- responds to $94 \%$, an intracranial haemorrhage risk of $0.1 \%$ year corresponds to $99 \%$ and 0 units of alcohol/day corresponds to $89 \%$ who would still choose OAC [22]. Although most physicians will acknowledge its importance, practical and evidence-based methods of shared decision making in AF patients are an unmet need (Table 1).

\section{Choosing anticoagulation: aspirin is no suitable alternative}

The downside of any antithrombotic drug is the increase of the patients' intrinsic bleeding risk. Undeniably, fear for bleeding has caused physicians to choose aspirin over VKA for perceived lower bleeding risk. However, it is important to realise that there is no relationship between a drug's ability to prevent stroke and its potential to harm through bleeding (safety paradox). In fact, irrespective of age, aspirin use in AF patients is associated with a similar rate of major bleeding events compared with VKA but with significantly inferior stroke protection [23, 24]. This also holds true for the eldest elderly ( $n=366 \geq 85$ years): aspirin vs. apixaban, $4.9 \%$ vs. $4.7 \%$ major bleeding events and $7.5 \%$ vs. $1.0 \%$ strokes, respectively, per year in one study [19]. Furthermore, the combination of aspirin with clopidogrel also provides inferior stroke protection in $\mathrm{AF}$ patients compared with VKA [25]. Finally, OAC is the only antithrombotic regimen that reduces all-cause death [26].

Thus, even in AF patients with a low stroke risk (i.e. $\mathrm{CHA}_{2} \mathrm{DS}_{2}$ VASc score $<2$ in men and $<3$ in women), aspirin is not a suitable alternative, it warrants either no antithrombotic therapy or OAC [2]. However, we should keep in mind 
Table 2 Registered randomised clinical trials on long-term antithrombotic management of atrial fibrillation

\begin{tabular}{|c|c|c|c|c|c|}
\hline Trial number & Start & End & Title & Acronym & $n$ \\
\hline NCT02928133 & 04.2014 & 05.2018 & $\begin{array}{l}\text { NOACs for Atrial Tachyarrhythmias in Congenital Heart Dis- } \\
\text { ease }\end{array}$ & NOTE & 300 \\
\hline NCT01994265 & 10.2014 & 05.2018 & $\begin{array}{l}\text { Cognitive Impairment Related to Atrial Fibrillation Prevention } \\
\text { Trial }\end{array}$ & GIRAF & 200 \\
\hline NCT02941978 & 12.2015 & 05.2018 & $\begin{array}{l}\text { Motivational Interviewing to Support Oral AntiCoagulation } \\
\text { Adherence in Patients With Non-valvular Atrial Fibrillation }\end{array}$ & MISOAC-AF & 1000 \\
\hline NCT02690649 & 01.2016 & 06.2018 & $\begin{array}{l}\text { Keep it SIMPLE: Improving Anti-Coagulation Medication } \\
\text { Adherence }\end{array}$ & & 250 \\
\hline NTR5532 & 01.2016 & 08.2018 & $\begin{array}{l}\text { Management of Atrial fibriLLation INcluding tailoring of anti- } \\
\text { coagulation in patients from primary care }\end{array}$ & ALL-IN & 1000 \\
\hline NCT03174093 & 06.2017 & 11.2018 & Mhealth Application for anTicoagulation Care in Atrial & MATCh AFib & 200 \\
\hline NCT02889562 & 09.2016 & 12.2018 & $\begin{array}{l}\text { Apixaban Versus Warfarin for the Management of Post-opera- } \\
\text { tive Atrial Fibrillation }\end{array}$ & & 56 \\
\hline NCT02666157 & 01.2016 & 12.2018 & $\begin{array}{l}\text { Comparison of Efficacy and Safety Among Dabigatran, Ri- } \\
\text { varoxaban, and Apixaban in Non-Valvular Atrial Fibrillation }\end{array}$ & DARING-AF & 3672 \\
\hline NCT02933697 & 04.2017 & 04.2019 & $\begin{array}{l}\text { Compare Apixaban and Vitamin-K Antagonists in Patients With } \\
\text { Atrial Fibrillation (AF) and End-Stage Kidney Disease (ESKD) }\end{array}$ & AXADIA & 222 \\
\hline NCT02618577 & 02.2016 & 05.2019 & $\begin{array}{l}\text { Non-vitamin K Antagonist Oral Anticoagulants in Patients With } \\
\text { Atrial High Rate Episodes }\end{array}$ & $\mathrm{NOAH}$ & 3400 \\
\hline NCT02942407 & 12.2016 & 05.2019 & $\begin{array}{l}\text { Trial to Evaluate Anticoagulation Therapy in Hemodialysis } \\
\text { Patients With Atrial Fibrillation }\end{array}$ & RENAL-AF & 762 \\
\hline NCT03126214 & 05.2017 & 09.2019 & $\begin{array}{l}\text { Improving Stroke Prevention in Atrial Fibrillation Through } \\
\text { Pharmacist Prescribing }\end{array}$ & PIAAF Rx & 370 \\
\hline NCT02998905 & 04.2017 & 01.2020 & $\begin{array}{l}\text { NOACs for Stroke Prevention in Patients With Atrial Fibrilla- } \\
\text { tion and Previous ICH (NASPAF-ICH) }\end{array}$ & NASPAF-ICH & 100 \\
\hline NCT02426944 & 04.2015 & 05.2020 & $\begin{array}{l}\text { Left Atrial Appendage Closure vs. Novel Anticoagulation } \\
\text { Agents in Atrial Fibrillation }\end{array}$ & PRAGUE-17 & 400 \\
\hline NCT02961348 & 02.2017 & 12.2020 & $\begin{array}{l}\text { TIMING of Oral Anticoagulant Therapy in Acute Ischemic } \\
\text { Stroke With Atrial Fibrillation }\end{array}$ & & 3000 \\
\hline NCT02387229 & 03.2015 & 02.2021 & $\begin{array}{l}\text { Blinded Randomized Trial of Anticoagulation to Prevent Is- } \\
\text { chemic Stroke and Neurocognitive Impairment in AF }\end{array}$ & BRAIN-AF & 6396 \\
\hline NCT03061006 & 04.2017 & 04.2021 & $\begin{array}{l}\text { Impact of Anticoagulation Therapy on the Cognitive Decline } \\
\text { and Dementia in Patients With Non-Valvular Atrial }\end{array}$ & CAF & 120 \\
\hline NCT01938248 & 05.2015 & 04.2021 & $\begin{array}{l}\text { Apixaban for the Reduction of Thrombo-Embolism in Patients } \\
\text { With Device-Detected Sub-Clinical Atrial Fibrillation }\end{array}$ & ARTESiA & 4000 \\
\hline NCT03148457 & 07.2017 & 07.2021 & $\begin{array}{l}\text { Early Versus Late Initiation of Direct Oral Anticoagulants in } \\
\text { Post-ischaemic Stroke Patients With Atrial fibrillatioN (ELAN): } \\
\text { an International, Multicentre, Randomised-controlled, Two-arm, } \\
\text { Assessor-blinded Trial }\end{array}$ & ELAN & 2000 \\
\hline NCT03021928 & 06.2017 & 08.2021 & $\begin{array}{l}\text { Optimal Delay Time to Initiate Anticoagulation After Ischemic } \\
\text { Stroke in Atrial Fibrillation }\end{array}$ & START & 1000 \\
\hline NCT03129490 & 04.2017 & 09.2021 & $\begin{array}{l}\text { The Danish Non-vitamin K Antagonist Oral Anticoagulation } \\
\text { Study in Patients With Atrial Fibrillation }\end{array}$ & DANNOAC-AF & 11000 \\
\hline NCT02168829 & 01.2016 & 12.2021 & $\begin{array}{l}\text { Optimal Anticoagulation for Higher Risk Patients Post-Catheter } \\
\text { Ablation for Atrial Fibrillation Trial }\end{array}$ & OCEAN & 1452 \\
\hline NCT02886962 & 01.2017 & 01.2023 & Oral Anticoagulation in Haemodialysis Patients & AVKDIAL & 6396 \\
\hline NCT02928497 & 02.2017 & 12.2023 & $\begin{array}{l}\text { Assessment of the WATCHMANTM Device in Patients Unsuit- } \\
\text { able for Oral Anticoagulation }\end{array}$ & ASAP-TOO & 888 \\
\hline NCT02830152 & 05.2017 & 05.2030 & $\begin{array}{l}\text { Prevention of Stroke by Left Atrial Appendage Closure in } \\
\text { Atrial Fibrillation Patients After Intracerebral Hemorrhage }\end{array}$ & & 750 \\
\hline NCT02565693 & 09.2014 & & $\begin{array}{l}\text { Apixaban Versus Antiplatelet Drugs or no Antithrombotic } \\
\text { Drugs After Anticoagulation-associated Intracerebral Haem- } \\
\text { orrhage in Patients With Atrial Fibrillation }\end{array}$ & APACHE-AF & 100 \\
\hline
\end{tabular}



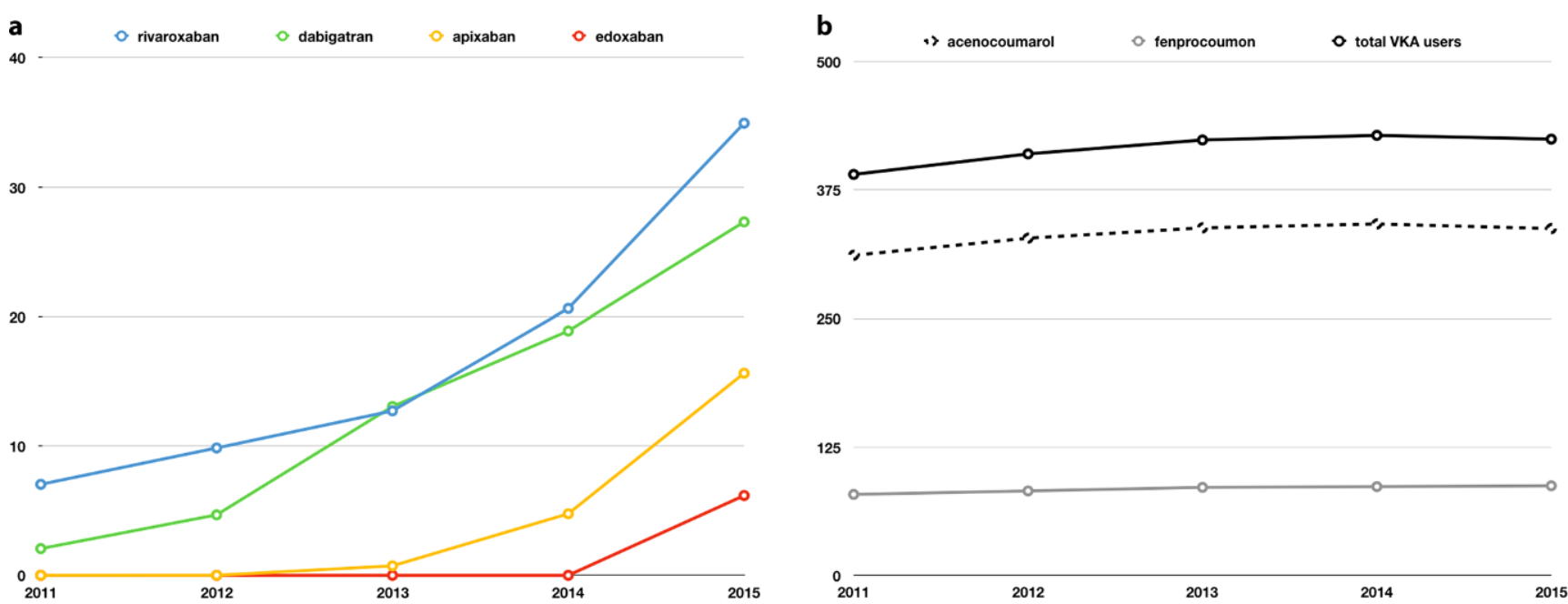

Fig. 3 Prescription rates of non-vitamin K antagonist oral anticoagulants (a) and vitamin K antagonists (b) in the Netherlands

tion, periodic assessment of modifiable bleeding risk factors and renal function seems appropriate because it matters for safety and/or dose recommendation for all NOACs. Another important aspect is education, of both patient and physician, and interdisciplinary communication. There appears to be room for improvement [36] as suggested by the outcome from a recent cluster RCT investigating an educational intervention program [37]. Of the 371 control group patients with a long-term indication for OAC only $5.9 \%$ was aware of medical emergencies (e.g. melena or signs suggestive of stroke). Knowledge was also scarce regarding what analgesics are safest to use (15.4\%), what to do after a missed dose $(19.9 \%)$, when to inform others about their OAC use $(23.9 \%)$ and target international normalised ratio (45.5\%) [37]. On the upside, the educational intervention significantly increased the knowledge level which sustained up to 24 months in that study [37].

\section{Antithrombotic management following major bleeding and stroke}

As pointed out by Maikranz et al. [37] it appears that very few patients with long-term OAC know how to act in case of unexpected major bleeding events. However, it is important to realise (and communicate) that these major events occur despite optimal preventive measures and to discuss with the patient how to act.

A predominantly upper gastrointestinal bleeding is the most frequent major bleeding complication in patients using long-term antithrombotic treatment, both aspirin and OAC [38]. Although gastrointestinal bleeding in itself is often non-fatal, it is a prognostic marker as reflected by a death rate of $30-35 \%$ in two years following the index event $[39,40]$. Restarting OAC following a gastrointestinal bleeding is the only regimen associated with both a very sig- nificant reduction of all-cause mortality [39-43] and stroke. Although the risk of major bleeding increases with reinitiating OAC, the risk of a recurrent gastrointestinal bleed does not $[39,40]$, except in patients with end-stage renal disease [43]. In case of repetitive gastrointestinal bleeding, quality of life also plays an important role in the shared decision to whether or not restart OAC therapy. Furthermore, it is important to take the potential mechanism into account. For instance, esophagogastroduodenoscopy confirmed ulcer healing before initiation of OAC significantly reduces the rate of major bleeding [44]. Also, good ( $>65 \%)$ opposed to poor $(<65 \%)$ TTR did not increase the risk of a recurrent ulcer bleeding but provided better stroke prevention [42]. The optimal time window of reinitiating OAC following gastrointestinal bleeding remains unclear. Qureshi et al. found that restarting OAC seven compared with thirty days after a gastrointestinal bleeding did not increase the risk of major bleeding but was associated with lower mortality and stroke rates [39].

Regarding the most feared and fatal bleeding complication, intracranial haemorrhage, a Danish nationwide study revealed that AF patients who survived the initial six weeks following an intracranial haemorrhage had a substantial reduction of all-cause mortality and stroke compared with no OAC during one-year follow-up (hazard ratio 0.55 , confidence interval 0.39-0.78) [45]. A Swedish nationwide study showed that of the surviving 1,454 patients of a first intracranial haemorrhage under OAC, $10.4 \%$ resumed OAC within three and $21.2 \%$ within twelve months [46]. Oral anticoagulants should probably not be resumed in patients with a lobar intracerebral haemorrhage caused by cerebral amyloid angiopathy, given the high risk (3-14\% within one year) of recurrent intracranial haemorrhage [47]. Although RCTs answering the question whether and when to resume antithrombotic medication in patients who suffered an in- 
Fig. 4 Reporterd side-effects of non-vitamin $\mathrm{K}$ antagonist oral anticoagulants (a) and vitamin $\mathrm{K}$ antagonists (b) in the Netherlands (a Source: www.lareb. $\mathrm{nl}$; updated 4.7.17. At this moment in time too few side-effects regarding edoxaban were reported to portrait a breakdown., b Source: www.gipdatabank.nl; updated 22.11.16) a

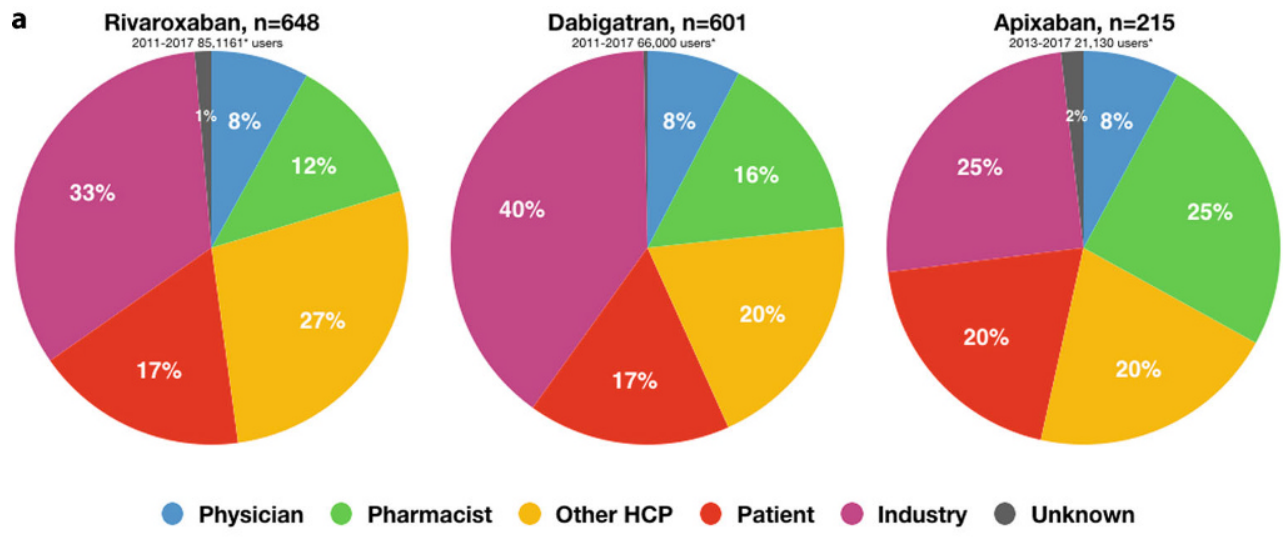

b
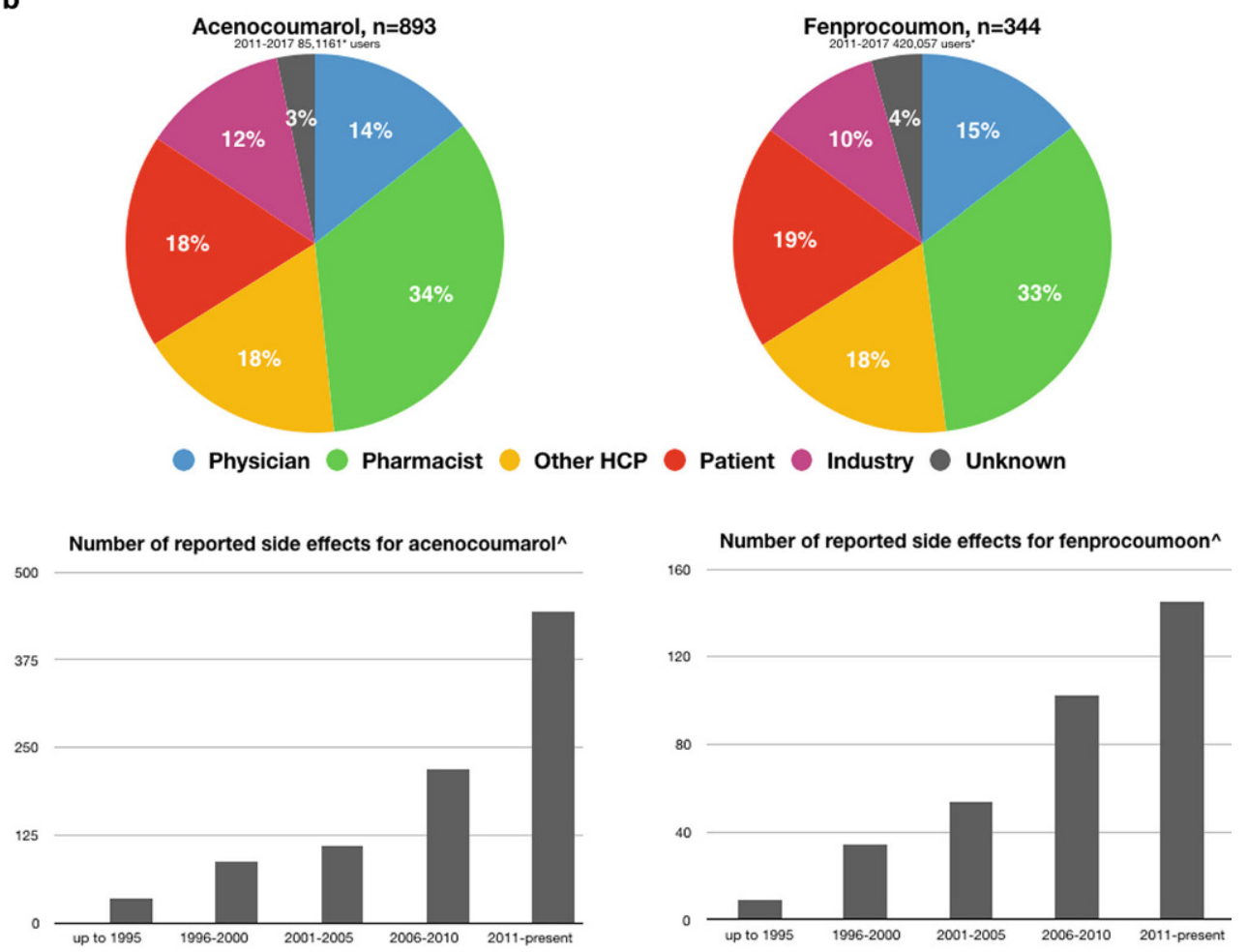

tracranial haemorrhage are lacking, one is currently recruiting in the Netherlands (APACHE AF trial) (Table 2). Hence, resuming antithrombotic medication should be a multidisciplinary decision, involving a cardiologist, neurologist and a geriatric specialist or general practitioner [48].

Early stroke recurrence of cardioembolic origin is as high as $14 \%$ within two weeks. OAC substantially reduces this risk. Even, or perhaps especially, the eldest elderly benefit as Appelros et al. demonstrated a reduced all-cause mortality and stroke rate in nonagenarians (between 90 and 100 years of age) [49]. Initiation of OAC monotherapy, which outperforms low-molecular-weight heparin alone or followed by OAC, 4-14 days following the index stroke opposed to outside this window provides the best protection against recurrent stroke [50]. Perhaps beside the use of the National Institutes of Health stroke severity scale [2], the novel ALESSA score might assist in deciding upon early initiation or re-initiation [51].

Side effects could trigger incorrect or non-use of OAC leading to a vicious circle. It therefore deserves special attention during follow-up. However, it seems as if a magnifying glass is being held over the side effects of NOACs as reflected by the registration in the Netherlands (Lareb). Interestingly, the industry filed most (35\%) of the reports followed by patients $(17-20 \%)$ and pharmacists $(16 \%)$, whereas physicians $(8 \%)$ provided the least of the reports. In the Netherlands, rivaroxaban and dabigatran became available in 2011, followed by apixaban (2013) 
and edoxaban (2015) (Fig. 3a). Since then, the Netherlands pharmacovigilance centre Lareb received a total of 1,487 (609 were severe) side effect notifications among 84,047 NOAC users. A NOAC specific breakdown is displayed in Fig. 4a. During the same time period (2011-present) among the $>400,000$ VKA users (Fig. 3b) Lareb received a total of 1,237 (366 were severe) side effect reports (Fig. 4b). Perhaps, this provides food for thought on how we can optimise the monitoring and reporting of long-term side effects in the near future. Furthermore, results of real-life studies and registries are instrumental in understanding how new therapies find their way in daily clinical practice and for the identification of pitfalls.

Several ongoing and future trials will also provide answers on current knowledge gaps (Table 2).

\section{End of long-term antithrombotic management}

The rate of OAC use only declines despite an increasing risk of stroke over time [11, 52]. Until recently this was partly driven by the fact that there was no suitable alternative for VKA treatment. Many of the previously discussed aspects such as patient education, frailty, reduced life expectancy, stroke, major bleeding or drug specific side effects contribute to the withholding or permanent discontinuation of OAC. In the contemporary RCTs permanent OAC discontinuation was roughly $20 \%$ in two years, with a higher rate of cessation in the first year of follow-up. Permanent discontinuation occurred significantly more with dabigatran and significantly less with apixaban compared with warfarin and aspirin [24, 53, 54]. In 'real life', permanent discontinuation can be as low as $20 \%$ in five years, even in the VKA-naive eldest elderly [55]. Despite the previously discussed superior reduction of all-cause mortality and stroke, in selected patients OAC is permanently discontinued after a careful shared decision process, similar to deactivating the defibrillator capacity of the ICD. However, literature to support best practice on this topic is lacking.

\section{Conclusions}

Current clinical knowledge and evidence concerning optimal long-term antithrombotic management of AF patients provide clear recommendations for the majority of patients. However, a relentless suboptimal use of OAC remains a major concern, especially in the elderly. Several ongoing RCTs aim to fill 'the knowledge gap' in specific patient groups or situations concerning the start, continuation or discontinuation of OAC. Still, important unmet needs are improved education, guidance on shared decision making [56], as- sessment and impact of frailty, and prospective registries of daily clinical practice, such as DUTCH-AF (Project number 848050006, ZonMw-programma Goed Gebruik Geneesmiddelen).

Funding No funds were received in support of this manuscript.

Conflict of interest R. Pisters, A. Elvan, H.J.G.M. Crijns and M.E.W. Hemels declare that they have no competing interests.

Open Access This article is distributed under the terms of the Creative Commons Attribution 4.0 International License (http:// creativecommons.org/licenses/by/4.0/), which permits unrestricted use, distribution, and reproduction in any medium, provided you give appropriate credit to the original author(s) and the source, provide a link to the Creative Commons license, and indicate if changes were made.

\section{References}

1. Wolf PA, Abbott RD, Kannel WB. Atrial fibrillation as an independent risk factor for stroke: the Framingham Study. Stroke. 1991;22:983-8.

2. Kirchhof P, Benussi S, Kotecha D, et al. ESC AF 2016. Eur Heart J. 2016;37:2893-962.

3. Pisters R, van Oostenbrugge RJ, Knottnerus ILH, et al. The likelihood of decreasing strokes in atrial fibrillation patients by strict application of guidelines. Europace. 2010;12:779-84.

4. Ahlsson A, Fengsrud E, Bodin L, Englund A. Postoperative atrial fibrillation in patients undergoing aortocoronary bypass surgery carries an eightfold risk of future atrial fibrillation and a doubled cardiovascular mortality. Eur J Cardiothorac Surg. 2010;37:1353-9.

5. Erküner Ö, Rienstra M, Van Gelder IC, et al. Stroke risk in patients with device-detected atrial high-rate episodes. Neth Heart J. 2017;17:1323-5.

6. Van Gelder IC, Healey JS, Crijns HJGM, et al. Duration of devicedetected subclinical atrial fibrillation and occurrence of stroke in ASSERT. Eur Heart J. 2017;38:1339-44.

7. Camm AJ, Simantirakis E, Goette A, et al. Atrial high-rate episodes and stroke prevention. Europace. 2017;19:169-79.

8. Khan IA. Atrial stunning: determinants and cellular mechanisms. Am Heart J. 2003;145:787-94.

9. Berger M, Schweitzer P. Timing of thromboembolic events after electrical cardioversion of atrial fibrillation or flutter: a retrospective analysis. Am J Cardiol. 1998;82:1545-7-A8.

10. Manning WJ, Silverman DI, Katz SE, et al. Impaired left atrial mechanical function after cardioversion: relation to the duration of atrial fibrillation. J Am Coll Cardiol. 1994;23:1535-40.

11. Marinigh R, Lip GYH, Fiotti N, et al. Age as a risk factor for stroke in atrial fibrillation patients. J Am Coll Cardiol. 2010;56:827-37.

12. Weijs B, Pisters R, Haest RJ, et al. Patients originally diagnosed with idiopathic atrial fibrillation more often suffer from insidious coronary artery disease compared to healthy sinus rhythm controls. Heart Rhythm. 2012;9:1923-9.

13. Scowcroft ACE, Lee S, Mant J. Thromboprophylaxis of elderly patients with AF in the UK: an analysis using the General Practice Research Database (GPRD) 2000-2009. Heart. 2013;99:127-32.

14. Lefebvre M-CD, St-Onge M, Glazer-Cavanagh M, et al. The effect of bleeding risk and frailty status on anticoagulation patterns in octogenarians with atrial fibrillation: the FRAIL-AF study. Can J Cardiol. 2016;32:169-76.

15. Induruwa I, Evans NR, Aziz A, et al. Clinical frailty is independently associated with non-prescription of anticoagulants in older patients with atrial fibrillation. Geriatr Gerontol Int. 2017;27:1765. 
16. Pisters R. A novel user-friendly score (HAS-BLED) to assess 1-year risk of major bleeding in patients with atrial fibrillation. Chest. 2010;138:1093-100.

17. Jaspers Focks J, van Vugt SPG, Albers-Akkers MTH, et al. Low performance of bleeding risk models in the very elderly with atrial fibrillation using vitamin $\mathrm{K}$ antagonists. J Thromb Haemost. 2016;14:1715-24.

18. Poli D, Antonucci E, Testa S, et al. Bleeding risk in very old patients on vitamin $\mathrm{K}$ antagonist treatment: results of a prospective collaborative study on elderly patients followed by Italian Centres for Anticoagulation. Circulation. 2011;124:824-9.

19. Ng KH, Shestakovska O, Connolly SJ, et al. Efficacy and safety of apixaban compared with aspirin in the elderly: a subgroup analysis from the AVERROES trial. Age Ageing. 2016;45:77-83.

20. Poli D, Antonucci E, Grifoni E, et al. Bleeding risk during oral anticoagulation in atrial fibrillation patients older than 80 years. J Am Coll Cardiol. 2009;54:999-1002.

21. Protheroe J, Fahey T, Montgomery AA, Peters TJ. The impact of patients' preferences on the treatment of atrial fibrillation: observational study of patient based decision analysis. BMJ. 2000;320:1380-4.

22. Fuller R, Dudley N, Blacktop J. Avoidance hierarchies and preferences for anticoagulation - semi-qualitative analysis of older patients' views about stroke prevention and the use of warfarin. Age Ageing. 2004;33:608-11.

23. Mant J, Hobbs FR, Fletcher K, et al. Warfarin versus aspirin for stroke prevention in an elderly community population with atrial fibrillation (the Birmingham Atrial Fibrillation Treatment of the Aged Study, BAFTA): a randomised controlled trial. Lancet. 2007;370:493-503.

24. Connolly SJ, Eikelboom J, Joyner C, et al. Apixaban in patients with atrial fibrillation. N Engl J Med. 2011;364:806-17.

25. ACTIVE Writing Group of the ACTIVE Investigators, Connolly S, et al. Clopidogrel plus aspirin versus oral anticoagulation for atrial fibrillation in the Atrial fibrillation Clopidogrel Trial with Irbesar$\tan$ for prevention of Vascular Events (ACTIVE W): a randomised controlled trial. Lancet. 2006;367:1903-12.

26. Wolff A, Shantsila E, Lip GYH, Lane DA. Impact of advanced age on management and prognosis in atrial fibrillation: insights from a population-based study in general practice. Age Ageing. 2015;44:874-8.

27. Staerk L, Gerds TA, Lip GYH, et al. Standard and reduced doses of dabigatran, rivaroxaban and apixaban for stroke prevention in atrial fibrillation: a nationwide cohort study. J Intern Med. 2018;283:45-55.

28. Steinberg BA, Shrader P, Thomas L, et al. Off-label dosing of nonvitamin $\mathrm{K}$ antagonist oral anticoagulants and adverse outcomes: the ORBIT-AF II Registry. J Am Coll Cardiol. 2016;68:2597-604.

29. Wehling M, Collins R, Gil VM, et al. Appropriateness of Oral Anticoagulants for the Long-Term Treatment of Atrial Fibrillation in Older People: results of an evidence-based review and international consensus validation process (OAC-FORTA 2016). Drugs Aging. 2017;34:499-507.

30. Kilickiran Avci B, Vatan B, Tok OO, et al. The trends in utilizing nonvitamin $\mathrm{K}$ antagonist oral anticoagulants in patients with nonvalvular atrial fibrillation: a real-life experience. Clin Appl Thromb Hemost. 2015;22(8):785-91.

31. Yao X, Abraham NS, Alexander GC, et al. Effect of adherence to oral anticoagulants on risk of stroke and major bleeding among patients with atrial fibrillation. J Am Heart Assoc. 2016;5:e3074-12.

32. Pisters R, van Vugt SPG, Brouwer MA, et al. Real-life use of Rivaroxaban in the Netherlands: data from the Xarelto for Prevention of Stroke in Patients with Atrial Fibrillation (XANTUS) registry. Neth Heart J. 2017;364:806-8.
33. Giugliano RP, Ruff CT, Braunwald E, et al. Edoxaban versus warfarin in patients with atrial fibrillation. N Engl J Med. 2013;369: 2093-104.

34. Alexander JH, Andersson U, Lopes RD, et al. Apixaban $5 \mathrm{mg}$ twice daily and clinical outcomes in patients with atrial fibrillation and advanced age, low body weight, or high creatinine. JAMA Cardiol. 2016;1(6):673-81. https://doi.org/10.1001/jamacardio.2016.1829.

35. Beasley BN, Unger EF, Temple R. Anticoagulant options - why the FDA approved a higher but not a lower dose of dabigatran. N Engl J Med. 2011;364:1788-90.

36. Clarkesmith DE, Pattison HM, Khaing PH, Lane DA. Educational and behavioural interventions for anticoagulant therapy in patients with atrial fibrillation. Chichester: John Wiley \& Sons, Ltd; 1996. Lane DA, ed.

37. Maikranz V, Siebenhofer A, Ulrich L-R, et al. Does a complex intervention increase patient knowledge about oral anticoagulation? a cluster-randomised controlled trial. BMC Fam Pract. 2017;18:15.

38. Ashburner JM, Go AS, Reynolds K, et al. Comparison of frequency and outcome of major gastrointestinal hemorrhage in patients with atrial fibrillation on versus not receiving warfarin therapy (from the ATRIA and ATRIA-CVRN cohorts). Am J Cardiol. 2015;115:40-6.

39. Qureshi W, Mittal C, Patsias I, et al. Restarting anticoagulation and outcomes after major gastrointestinal bleeding in atrial fibrillation. Am J Cardiol. 2014;113:662-8.

40. Staerk L, Lip GYH, Olesen JB, et al. Stroke and recurrent haemorrhage associated with antithrombotic treatment after gastrointestinal bleeding in patients with atrial fibrillation: nationwide cohort study. BMJ. 2015;351:h5876.

41. Sengupta N, Feuerstein JD, Patwardhan VR, et al. The risks of thromboembolism vs. recurrent gastrointestinal bleeding after interruption of systemic anticoagulation in hospitalized inpatients with gastrointestinal bleeding: a prospective study. Am J Gastroenterol. 2015; 110:328-35.

42. Lee S-J, Sung J-H, Kim J-B, et al. The safety and efficacy of vitamin $\mathrm{K}$ antagonist in atrial fibrillation patients with previous ulcer bleeding: long-term results from a multicenter study. Medicine (Baltimore). 2016;95:e5467.

43. Khalid F, Qureshi W, Qureshi S, et al. Impact of restarting warfarin therapy in renal disease anticoagulated patients with gastrointestinal hemorrhage. Ren Fail. 2013;35:1228-35.

44. Lee S-J, Shin D-H, Hwang H-J, et al. Bleeding risk and major adverse events in patients with previous ulcer on oral anticoagulation therapy. Am J Cardiol. 2012;110:373-7.

45. Bronnum Nielsen P. Restarting anticoagulant treatment after Intracranial hemorrhage in patients with atrial fibrillation and the impact on recurrent stroke, mortality, and bleeding. Circulation. 2015;132(6):517-25. https://doi.org/10.1161/CIRCULATIONAHA. 115.015735 .

46. Pennlert J, Asplund K, Carlberg B, et al. Antithrombotic treatment following intracerebral hemorrhage in patients with and without atrial fibrillation. Stroke. 2015;46:2094-9.

47. Poon MTC, Fonville AF, Al-Shahi Salman R. Long-term prognosis after intracerebral haemorrhage: systematic review and meta-analysis. J Neurol Neurosurg Psychiatr. 2014;85:660-7.

48. Kappelle LJJ, Hofmeijer J, Chamuleau SA, et al. Resumption of antithrombotic treatment after an intracerebral haemorrhage. Ned Tijdschr Geneeskd. 2015;159:A8507.

49. Appelros P, Farahmand B, Terént A, Åsberg S. To treat or not to treat. Stroke. 2017;48:1617-23.

50. Paciaroni M, Agnelli G, Falocci N, et al. Early recurrence and cerebral bleeding in patients with acute ischemic stroke and atrial fibrillation: effect of anticoagulation and its timing: the RAF study. Stroke. 2015;46:2175-82.

51. Paciaroni M, Agnelli G, Caso V, et al. Prediction of early recurrent thromboembolic event and major bleeding in patients with acute 
stroke and atrial fibrillation by a risk stratification schema: the ALESSA Score Study. Stroke. 2017;48:726-32.

52. Leyden JM, Kleinig TJ, Newbury J, et al. Adelaide stroke incidence study: declining stroke rates but many preventable cardioembolic strokes. Stroke. 2013;44:1226-31.

53. Connolly SJ, Ezekowitz MD, Yusuf S, et al. Dabigatran versus warfarin in patients with atrial fibrillation. $\mathrm{N}$ Engl $\mathrm{J}$ Med. 2009;361:1139-51.

54. Granger CB, Alexander JH, McMurray JJV, et al. Apixaban versus warfarin in patients with atrial fibrillation. $\mathrm{N}$ Engl $\mathrm{J}$ Med. 2011;365:981-92.
55. Bertozzo G, Zoppellaro G, Granziera S, et al. Reasons for and consequences of vitamin $\mathrm{K}$ antagonist discontinuation in very elderly patients with non-valvular atrial fibrillation. J Thromb Haemost. 2016;14:2124-31.

56. Steffel J, Verhamme P, Potpara TS, et al. The 2018 European Heart Rhythm Association practical guide on the use of non-vitamin K antagonist oral anticoagulation in patients with atrial fibrillation. Eur Heart J. 2018; https://doi.org/10.1093/eurheartj/ehy136.

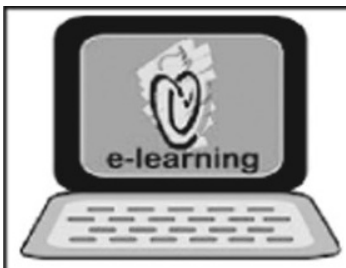

After finishing the questions you will be asked to fill in your name, hospital and e-mail address; then press the button 'verzenden'.

When 6 out of the 10 questions are answered correctly, you acquire 1 accreditation point granted by the Quality Committee of the Netherlands Society of Cardiology (NVVC). The acquired point will be credited to your personal file in the GAIA system. You will also receive an e-mail with all the correct answers.

Over a period of one year 10 e-learning articles will appear in 10 subsequent NHJ editions. In each edition the e-learning article will be recognisable by a special icon. On an annual basis you can collect 10 accreditation points. The accreditation points are credited in the GAIA system by the CVOI.

If you need additional information, please contact the CVOI by e-mail: cvoi@cvoi.org or by phone: 030-2345001.

\section{J. J. Piek}

Chief editor NHJ
K.B. Schick

Coordinator CVOI 